\title{
Phytoprotection
}

\section{Résumés de communications}

Volume 86, numéro 2, août 2005

URI : https://id.erudit.org/iderudit/012514ar

DOI : https://doi.org/10.7202/012514ar

Aller au sommaire du numéro

\section{Éditeur(s)}

Société de protection des plantes du Québec (SPPQ)

ISSN

0031-9511 (imprimé)

1710-1603 (numérique)

Découvrir la revue

Citer cet article

(2005). Résumés de communications. Phytoprotection, 86(2), 135-147.

https://doi.org/10.7202/012514ar d'utilisation que vous pouvez consulter en ligne.

https://apropos.erudit.org/fr/usagers/politique-dutilisation/ 


\section{$31^{\mathrm{e}}$ Congrès international sur la carotte $31^{\text {st }}$ International Carrot Conference}

Longueuil (Québec, Canada), 11 au 14 septembre 2005 Longueuil (Quebec, Canada), September 11 to 14, 2005

\section{Effect of onion and winter cover crops on Meloidogyne hapla densities and subsequent carrot yields}

G. Bélair and Y. Fournier. Agriculture and AgriFood Canada, Horticultural Research and Development Centre, Saint-Jean-sur-Richelieu (Quebec), Canada J3B 3E6

The effect of onion crop rotation and winter cover crops on root-knot nematode (Meloidogyne hapla) densities and subsequent carrot yields was determined under field microplot conditions in Quebec from 1996 to 2000. In two separate experiments, onion was either cropped once every two years or for two consecutive years, and then followed by two years of carrot. In both experiments, barley, sudangrass, oats, oilseed radish, pearl millet, phacelia, rye and white mustard were all evaluated as a winter cover crop and sown in late August in onion plots after harvest. Check plots included carrot monoculture without a winter cover crop and onion without a winter cover crop, with or without fall ploughing. In the alternate onion rotation system, cover crops were either ploughed late that same fall (late October) or killed the following spring by cultivation (mid May). Fall plough of cover crops had no significant effect on $M$. hapla densities when compared with spring cultivation. In the consecutive onion rotation system, fall $M$. hapla densities were significantly lower following onion (6 per $100 \mathrm{~cm}^{3}$ soil) when compared with carrot (1164 per $100 \mathrm{~cm}^{3}$ ). The following year, the percentages of marketable carrot were 92 and $51 \%$ following onion and carrot respectively. In the alternate onion rotation system, $M$. hapla densities were significantly lower following onion (14 per $100 \mathrm{~cm}^{3}$ ) when compared to carrot (1329 per $100 \mathrm{~cm}^{3}$ ) and average percentages of marketable carrot were 73 and $33 \%$ following onion and carrot, respectively. In both rotation systems, the inclusion of a winter cover crop had no effect on the final population of $M$. hapla and on subsequent carrot yield. An economic production of carrot for two consecutive years was not possible following onion where the percentage of marketable carrot dropped consistently below $60 \%$ the second year.

\section{Sensitivity of carrots to mechanical cultivation in organic soil}

D.L. Benoit ${ }^{1}$, M. Bélanger ${ }^{1}$, and F. Gorrias ${ }^{2}$. ${ }^{\prime}$ Agriculture and Agri-Food Canada, Horticultural Research and Development Centre, SaintJean-sur-Richelieu (Quebec), Canada J3B 3E6; ${ }^{2}$ Institut Universitaire de Technologie, Amiens, France

The impact of cultivation on carrot development must be documented before this practice can be integrated into carrot production systems as a viable alternative to herbicides. Our objective was to identify critical carrot stages sensitive to mechanical weeding that would result in stand reduction, quality and/or yield reduction in organic soil. The experiment was conducted at the experimental farm of Sainte-Clotilde (Quebec), Canada, as a split plot with three replications in 2003, and as a randomized complete block design with three replications in 2004. A blanket treatment of linuron was applied pre-emergence at 1.125 $\mathrm{kg}$ a.i. ha ${ }^{-1}$ and post-emergence at $2.25 \mathrm{~kg}$ a.i. ha ${ }^{-1}$ to control weeds throughout the season. Carrot cultivar Sugar Snax 54 was seeded in three rows spaced $60 \mathrm{~cm}$ apart, at 100 seeds per $\mathrm{m}$ in $1.8 \mathrm{~m} \times 8 \mathrm{~m}$ plots. Treatments were: 1) a control with no cultivation; 2) cultivation with a basket weeder (Budding $\mathrm{h}^{\mathrm{TM}}$ model C); 3) cultivation with a torsion weeder (rigid steel rods) with "Spyders" (spiked disks) on each side of the row (Bezzerides ${ }^{\mathrm{TM}}$ ); and 4) cultivation with a rototiller. Carrots were cultivated either with a single pass at the cotyledon (COT), 1 leaf (1L), 2 leaves (2L) or 3 leaves (3L) growth stages, or with multiple passes at the $C O T+1 \mathrm{~L}, \mathrm{COT}+2 \mathrm{~L}, 1 \mathrm{~L}+2 \mathrm{~L}, 2 \mathrm{~L}+3 \mathrm{~L}, \mathrm{COT}+1 \mathrm{~L}+2 \mathrm{~L}$, $1 \mathrm{~L}+2 \mathrm{~L}+3 \mathrm{~L}, \mathrm{COT}+1 \mathrm{~L}+2 \mathrm{~L}+3 \mathrm{~L}$ growth stages. Carrots were monitored by counting carrots in two permanent quadrats $(50 \mathrm{~cm} \times 50 \mathrm{~cm})$ located on the rows before and $5 \mathrm{~d}$ after each cultivation; by measuring carrot biomass within the quadrats $7 \mathrm{~d}$ after the last cultivation; and by evaluating carrot yield on $2 \mathrm{~m}$ rows at harvest. Cultivation with the basket weeder resulted in greater crop damage than with the other two cultivators. This was attributed to the proximity of the crop rows to the basket weeder $(10 \mathrm{~cm})$, especially at the early phenological crop stages. Any cultivation at the cotyledon stage resulted in reduced carrot stands, reduced mid-season biomass and reduced percentage of marketable yield. Consequently, mechanical weed control in carrots is an acceptable alternative to herbicides in organic soil as long as cultivation is scheduled when carrots are at the first true leaf stage or greater. The choice of cultivator is limited to implements that work at least $12 \mathrm{~cm}$ away from carrot rows. 


\section{Bioclimatic modelling of carrot phenology from seeding to root harvest}

G. Bourgeois, D. Plouffe, D. Choquette, M. Boivin, and N. Beaudry. Agriculture and AgriFood Canada, Horticultural Research and Development Centre, Saint-Jean-sur-Richelieu (Quebec), Canada J3B 3E6

Phenology is a key element for many crop management decisions such as pesticide timing, planning of seeding, harvest scheduling, irrigation, etc. A generic bioclimatic model was developed to predict the phenological stages of agricultural crops expressed in $\mathrm{BBCH}$, a universal scale using decimal code for the description of plant growth stages. Seeding, emergence, cotyledon, 9-leaves, tap root initiation and root harvest stages are designated by $\mathrm{BBCH}$ decimal codes $0,9,10,19,41$ and 49, respectively. To adapt the proposed phenological model to carrot, experiments were carried out in growth cabinets to establish the effect of soil temperature on carrot emergence and the effects of air temperature and photoperiod on leaf appearance rate. Temperature treatments in growth cabinets were $5,10,15,20,25,30$ and $35^{\circ} \mathrm{C}$, and photoperiod treatments were $6,9,12,15,18$ and $21 \mathrm{~h}$. Using the Brière equation for non-linear response to temperature, estimated lower, optimum and higher threshold temperatures were 0,27 and $35^{\circ} \mathrm{C}$. At optimum temperature, emergence occurred after $7 \mathrm{~d}$ and approximately one new leaf appeared every week. Leaf appearance rate increased slightly from short to long photoperiods. Non-linear regressions obtained from these experiments were implemented in the generic bioclimatic model which uses hourly weather data to predict daily $\mathrm{BBCH}$ stages. Data on carrot phenology from seeding to harvest were collected in field experiments to evaluate the potential of these $\mathrm{BBCH}$ predictions based on observed weather information. After calibration of the maximum leaf appearance rate parameter, the model predicted leaf production adequately in most field experiments. Additional research is required to adjust the timing of tap root initiation, development and harvest.

\section{Impact of three Pythium species on growth and development of carrot}

D. Breton ${ }^{1,3}$, C. Béasse ${ }^{2,3}$, M. Prunier ${ }^{3}$, and F. Montfort'. 'SILEBAN 50760 Barfleur, France; ${ }^{2}$ AIREL, 47110 Sainte-Livrade, France; ' INRA, UMR BiO3P, B.P. 35327-F-35653 Le Rheu cedex, France

Pythium are among the most important soil-borne pathogens of carrot in France and all over the world, seriously compromising the yield and quality of this crop. The major and most reported disease caused by these fungi undeniably is cavity spot, with two most often associated species: P. violae (P.V.) and P. sulcatum (P.s.). It is nevertheless reported that Pythium can cause other symptoms, forking for example, as shown by results in France demonstrating the capacity of some isolates of P.s. or P.v. to induce either forking or cavity spot symptoms. During the last $4 \mathrm{yr}$, a disease diagnostic survey on carrot crops in the southwest of France has underlined the diversity of symptoms due to Pythium (damping-off, forking, cavity spot) and shown the occurrence of two main species: P. sulcatum and P. coloratum (P.c.); $P$. violae was not isolated in this area. Species close to $P$. coloratum, such as $P$. dissotocum, $P$. diclinum or P.f., were assigned to the same $P$. coloratum group on the basis of RFLP patterns on the ITS (five restriction enzymes). During this survey, P.s. was mainly isolated from cavity spot lesions while P.c. was preferentially isolated from young plant roots. The first objective of this work was then to clarify the role of the P.c. isolates on carrot growth and development with laboratory and greenhouse experiments using isolates of P.v. and P.s. as references. In a first greenhouse experiment, soil was artificially infested with P.c. (nine isolates compared), P.s. or P.v.; we demonstrated that all the Pythium isolates significantly reduced the root weight in the first stages of development of the plant (42 d after sowing). Nevertheless, $90 \mathrm{~d}$ after sowing, this reduction was less important and significantly different from the control only for one isolate of P.C. and the isolate of P.v. In a second greenhouse experiment, soil was artificially infested with P.c. (three isolates compared) or P.s.; our results showed the capacity of P.s. to induce short roots (stopper-like roots) and the capacity of the three isolates of P.c. to induce forking roots. In both greenhouse experiments, damage due to early attacks on the main root apex was clearly induced, whatever the species. Later damage, i.e. cavity spot lesions, was induced by P.v. and P.s., whereas the association with P.c. was not so clear despite in vitro laboratory pathogenicity tests indicating that all the isolates could cause cavity spot lesions. These results give indications on the role of P.c. in southwestern France, but also raise questions about the methods to be used for evaluating the pathogenicity of various isolates of Pythium since methods have to fit with the type of damage studied.

\section{Alternaria leaf blight: a new technique for plant resistance screening \\ M. Briard and A. Pawelec. Institut National d'Horticulture, Research unit, 49045 Angers cedex 01, France}

Alternaria leaf blight (ALB), caused by the fungus Alternaria dauci, is a common disease of carrot throughout the world. The objective of the present study was to set up a technique for plant resistance screening to ALB in controlled environments. Greenhouse and laboratory screening methods were compared using three cultivars and $50 \mathrm{~F}_{2}$ genotypes segregating for ALB resistance. The results indicated the utility of a greenhouse evaluation and the inadequacy of detached leaf and hypocotyl assays for carrot screening of ALB resistance. Spearman's rank correlation made between results obtained with both $F_{2}$ plants and their progenies allowed to define the optimal evaluation stage with the greenhouse test, and proved the test to be powerful enough to be used as a pre-screening test in breeding programs. 
Carottes and carrots: tracing the origin!

L. Brodeur. PRISME Consortium, Sherrington (Quebec), Canada JOL 2NO

Do you know if your carrots are French or English? Their spellings are almost the same. Is it safe to eat an English carrot if you are promoting the independence of the province of Quebec? And if an English speaking person eats a French carrot, will he become bilingual or be turned into a frog? Do you need another spelling or just a lot number? Food safety and traceability issues are closely related. The marriage of businessmen, politicians and mad cows has forced all the food industry to comply with procedures and manuals developed with the Hazard Analysis and Critical Control Points (HACCP) method. The HACCP programs that are developed to guarantee food safety all end up with the same last step: you must have a recall procedure. Even if fresh market carrots are one of the safest products available at the grocery store, carrot growers and packers will have to invest time and money to implement HACCP programs and recall procedures. The conference will describe how carrot growers can keep track of the different carrot lots they produce, from the field to the consumer. It will also describe the information that can be attached to the lot number, how the information can be organized and analyzed to improve farm management, choice of cultivars, fertilizing practices, etc., and be used as well to answer the HACCP and customer requirements.

\section{Changes in quality of heat-treated carrot during long-term storage}

M.T. Charles, C. Vigneault, B. Goyette, I. Lemay, and D. Roussel. Agriculture and Agri-Food Canada, Horticultural Research and Development Centre, Saint-Jean-sur-Richelieu (Quebec), Canada J3B 3E6

Heat treatment of post-harvest commodities is a new approach that holds promise in controlling disease development during long-term storage. The most common methods used for heat application on horticultural crops are hot water dip or spray, vapour heat and hot air. The present study was conducted to evaluate the changes in quality of heat-treated carrots kept for 5 months under the optimal conditions recommended for long-term storage. Treatment application was with a prototype dispensing pressurized water vapour at $200 \mathrm{kPa}$. Environmental temperature was controlled by addition of more steam to compensate for the energy absorbed by the produce or lost through air infiltration or wall conductivity. Water vapour to air mixture was maintained stable and at the desired temperature before entering in contact with the roots by inserting the treatment chamber inside a water vapour-to-air pre-mix chamber. A forced air system was also used to circulate the pre-mixed heating medium through the mass of the produce. Several combinations of heat intensity and treatment duration were tested. Measured quality parameters were general appearance, firmness, surface browning, colour, total soluble solids (TSS) and disease development. Subjective scales were used for all quality parameters except for TSS, which was measured by refractometry. Changes in the appraised quality parameters were evaluated immediately after treatment, and after 1, 3 and 5 months of storage. Less disease developed on heat-treated roots. However, the low incidence of disease on control roots at the end of storage does not conclude to a positive effect of the treatment. The increase in TSS observed in the controls over the 5 months was less pronounced in all heat-treated roots. Treated carrots were firmer than the controls and had better colour and general appearance. However, the quality indexes reported were not significantly better than those reported for the control roots. Heat treatment did not have a negative impact on the evaluated quality parameters. The results seem to confirm that this treatment has a potential for long-term preservation of carrot and can be considered in a program where an upsurge of diseases during post-harvest storage can be predicted from data collected during field production.

\section{Evaluation of fungicides for control of cavity spot in a disease nursery}

J. Farrar. Department of Plant Science, California State University, Fresno, California, USA 937240

Cavity spot of carrot is one of the most important diseases of fresh market carrots. Although the cavity spot blemished are superficial, they decrease the cosmetic appeal of the carrot. Disease losses range from a low incidence of blemished carrots that must be sorted out during packaging to abandonment of fields due to high disease incidence. In California, cavity spot is caused by Pythium violae, P. ultimum, P. sulcatum, and $P$. irregulare. Replicated experiments on cavity spot disease controls are often hampered by the lack of a field location with consistently high disease incidence. In order to effectively and efficiently evaluate control methods, a cavity spot disease nursery was developed at the University Agriculture Laboratory of the California State University, in Fresno. The cavity spot disease nursery was established by growing three successive crops of susceptible carrots and inoculating with several isolates of $P$. violae, $P$. ultimum, and $P$. sulcatum. Inoculum was grown on sterilized milo and spread by hand throughout the field. At the end of the third consecutive carrot crop, a survey indicated a $3 \%$ disease incidence. During the fourth crop, the new fungicides Reason (fenamidone) and Ranman (cyazofamid) were compared with Ridomil Gold (mefanoxam) for control. Cavity spot incidence at harvest was not statistically different for the fungicides, and all fungicide treatments had significantly reduced incidence compared with the untreated control. Additional experiments are underway to examine fungicide rotation and application programs which include Reason, Ranman, and Ridomil Gold. Registration of Reason or Ranman would give carrot growers an alternative to Ridomil Gold. 
Field validation for a proposed forecast model for Sclerotinia rot of carrot

A.J. Foster', M.R. McDonald', and G.J. Boland'. 'Department of Plant Agriculture; ${ }^{2}$ Department of Environmental Biology, University of Guelph, Guelph (Ontario), Canada N1G 2W1

Field validation of a proposed forecasting system for management of Sclerotinia rot of carrot caused by Sclerotinia sclerotiorum was initiated in 2004 and repeated in 2005. Soil moisture, soil temperature, degree of canopy closure, number of senescing carrot leaves and number of infected plants were recorded in multiple commercial carrot fields each year and in an experimental plot in the Holland/Bradford Marsh region of Ontario. Inoculum levels were determined using Sclerotinia selective media and by scouting for apothecia below the canopy. These inoculum levels were used to determine the accuracy of the disease predictions. Fungicides boscalid and pyraclostrobin were applied according to the forecast model, a regime of calendar sprays, and based on a threshold limit used when scouting for inoculum. In 2004, the forecasting model successfully predicted the presence of Sclerotinia rot of carrot in all the commercial fields monitored and in the experimental plot. The model also successfully predicted the peak level of inoculum in all field sites. Application of fungicides had no significant effect on the incidence of disease at harvest, the area under the disease progress curve (AUDPC) or crop yields. Data from the 2005 field season and the 2004 storage trial will also be presented.

\section{Damage and management of the northern root- knot nematode on carrots in New York}

B.K. Gugino, G.S. Abawi, and J.W. Ludwig. Department of Plant Pathology, Cornell University, NYSAES, Geneva, New York, USA 14456

The northern root-knot nematode, Meloidogyne hapla, is an important pathogen of processing carrots throughout the production areas in New York. In the field, growth of infected carrots is uneven and patchy, and severely infected roots exhibit forking, galling on the main and fibrous roots, hairiness, and stubby roots. Depending on the level of soil infestation, marketable carrot yield has been reduced by as much as $43 \%$ in commercial fields where a nematicide was not applied; thus root-knot nematode damage may lead to great economic losses. In field microplots, the damage threshold density of $M$. hapla on carrots $\mathrm{cv}$. Oranza was 40 and 80 eggs per $100 \mathrm{cc}$ of mineral and organic soils, respectively. All commercial cultivars evaluated for resistance to $M$. hapla were found to be susceptible, although they exhibited differences in root-galling severity and in the level of nematode reproduction. Grain crops including corn, wheat, oat, rye, barley, and sudangrass hybrids are not hosts to M. hapla and are therefore effective rotational crops. In addition, green manures of sudangrass hybrids are suppressive to $M$. hapla through the production of toxic metabolites during decomposition in the soil. However, it is often not cost effective to rotate carrots with such grain crops which are often less profitable, especially on the high-value organic soils. Thus, chemical nematicides (primarily Vydate) are heavily relied upon for the management of root-knot nematode on carrots in New York. Extensive field evaluations have documented the cost effectiveness of Vydate applied at planting either by broadcast incorporation or as an in-furrow treatment to manage M. hapla and its damage in heavily infested soils. A simple soil bioassay with lettuce has been developed and extensively tested for the visual assessment of soil infestations with $M$. hapla utilizing a root-galling severity (RGS) scale of 1 (no visible galls, healthy roots) to 9 (>80\% of roots galled). An average RGS rating of approximately 2 or higher suggests the need to apply Vydate or to rotate with a non-host crop. The management of root-knot nematode on an as-needed basis and by employing multiple IPM-based tactics will improve carrot productivity and profitability as well as reduce negative environmental impact.

\section{Updating the development of an IPM program for carrot leaf blight management in New York B.K. Gugino, G.S. Abawi, and J.W. Ludwig. Department of Plant Pathology, Cornell University, NYSAES, Geneva, New York, USA 14456}

Leaf blight diseases are a major constraint to processing carrot production in New York. These diseases are caused by the fungi Alternaria dauci and Cercospora carotae and the bacterium Xanthomonas campestris pv. carotae. Yield losses due to these diseases can be considerable, especially if they occur early in the season and are ineffectively managed. In addition, severe defoliation and weakened foliage can result in reduced mechanical harvesting efficiency and reduced yield. In New York, chlorothalonil continues to be the fungicide most frequently applied. However, Amistar and Cabrio have recently become available and are increasingly being used. Previously, up to eight fungicide applications were made per season beginning in mid- to late June through midSeptember for the management of fungal leaf blights. Over the past $4 \mathrm{yr}$, the development and extensive evaluation and validation of several leaf blight management strategies for use in an integrated pest management program have been conducted in New York. These include the validation of the efficacy of the $25 \%$ disease incidence threshold level to prompt the first fungicide application. The need for subsequent fungicide applications was determined by either scouting weekly for changes in disease incidence and severity and monitoring of the forecasted weather for the following week or by using the Tom-Cast disease prediction model (15 DSV). Since there are no known cultivars resistant to leaf blight diseases, trials have also been conducted at the NYSAES Vegetable Research Farm in Geneva, NY, over the past 5 yr to identify more tolerant cultivars. The use of more tolerant cultivars in both research trials and in commercial grower fields has been shown to delay the need for the first fungicide application, thus reducing the number of fungicide applications recommended prior to harvest. Differences in disease severity ratings during the season and in the calculated area under the disease progress curve at the end of the season were demonstrated among cultivars grown in New York. 
The combined use of the disease scouting program and tolerant cultivars in addition to the recommended minimum 2-yr rotation out of carrots to facilitate the degradation of crop residues have reduced fungicide use by as much as $50 \%$ in some fields. The efficacy of various individual and combinations of fungicides, copper and plant activator compounds has also been evaluated for their use as part of the IPM program for carrot leaf blight management. Adoption of these IPM tactics by growers will enable growers in New York to more effectively manage leaf blight diseases while reducing production costs and adverse environmental impact.

\section{Drought tolerance mechanisms in carrot slicer varieties}

P. Joy and R. Lada. Processing Carrot Research Program, Nova Scotia Agricultural College, Department of Plant and Animal Sciences, Truro (Nova Scotia), Canada B2N 5E3

Evolution and ecology greatly contribute to species adaptation through the modification of physiological mechanisms. Survival of a crop species depends on the mechanisms it acquires throughout its evolution while adapting to specific conditions. Thus, each crop species/genotype will have one or several physiological mechanisms that dictate its success in a crop production system. Carrots occupy the second largest horticultural acreage in Nova Scotia and drought can severely impact the industry. Identifying a droughttolerant variety therefore is a very important step. While drought impact on carrot yield and quality is known, the mechanism of drought tolerance/sensitivity is less well understood. A mass greenhouse screening of 17 varieties (Bergen, Berlanda, Carachoice, Florida, HMX0331, Magnum, Nagadir, Nectar, Negovia, Neptune, Nereta, Niagra, Nikki, Oranza, Siroco, SX8503CE, and Tempo) of slicer carrots was conducted. Drought tolerance based on growth parameters and xylem pressure potential was investigated in order to discover the most drought hardy variety and to understand the underlying mechanisms. Xylem pressure potential (XPP) overall increased in response to water stress. XPP of control plants ranged from -0.4 to $-0.7 \mathrm{Mpa}$, while in waterstressed plants, a higher XPP of -0.5 to $-1.3 \mathrm{MPa}$ was observed. The greatest increase was seen in the variety Neptune, which significantly increased from -0.4 to $-1.3 \mathrm{MPa}$. The smallest increase, -0.4 to $-0.5 \mathrm{MPa}$, was observed in Nagadir. Overall growth during water stress was measured by the root/shoot ratio. Several varieties had positive responses in terms of higher root/shoot ratios that increased due to drought stress, including Berlanda, Carachoice, Magnum $(P<0.05)$, Oranza, Siroco, and Tempo. These varieties may therefore have developed mechanisms that promote growth during drought stress. Root/shoot ratios of all other varieties declined under drought stress with Bergen being the most sensitive and SX8503CE the least sensitive. Since XXP increased it may contribute to growth reduction in all varieties except those with the higher root/shoot ratios. Five varieties (Tempo, Oranza, Siroco, Bergen, and Neptune), based on preliminary data and popularity in the industry, were further selected and analyzed for gas exchange parameters, including photosynthesis $(\mathrm{Pn})$, stomatal conductance (Gs), and transpiration (Ti). Membrane injury index (MII) was also investigated. All varieties except Siroco showed a significant decline in $\mathrm{Pn}$ activity. Gs and Ti measurements showed no significant differences between control and water-stressed plants. In carrots, $\mathrm{Pn}$ seems to be more sensitive to water stress than other gas exchange parameters. Stomatal closure was less sensitive to drought stress than leaf growth or Pn. It may be hypothesized that non-stomatal components are responsible for the decrease in Pn, which may in turn lower leaf expansion and dry matter production and allocation. MII did not differ among varieties, thus revealing that the reduction in physiological functions did not occur via membrane dysfunction.

\section{Identification of duplicates for the optimization of carrot collection management \\ V. Le Clerc, A. Siel, and M. Briar. Institut National d'Horticulture, Research unit, 49045 Angers cedex 01, France}

On several occasions, molecular markers have proved their efficiency for the identification of duplicate accessions in genetic resource collections. To evaluate the use of molecular markers for the identification of carrot accession duplicates, 21 presumed duplicate accessions of "Jaune du Doubs" were selected. Only accessions that were not distinguished on a morphological basis were submitted to molecular analysis. Whatever the strategy employed, the crucial question was to determine the threshold required to declare whether accessions were duplicates or not. We used a strategy based on the comparison between intravarietal and intervarietal genetic distances. In order to save time and limit costs, DNA extractions were made on four to eight bulks of five individuals per accession, and the bulks were analyzed using 75 AFLP markers. An additional set of seven bulks was extracted from one accession to provide true control replicates. With the exception of the true duplicates, all the accessions were clearly identifiable. Based on these results, the following general strategy for the identification of carrot duplicates was proposed: seven bulks per accession will be analyzed with at least 70 AFLP markers if accessions are still considered as putative duplicates after a morphological characterization; accessions will be declared duplicates if one of their intravarietal genetic distances is higher than their intervarietal genetic distance.

\section{Incidence and severity of cavity spot on carrots with different pigments grown under different weather conditions}

M.R. McDonald', K. Vander Kooi', and P.W. Simon'. 'Department of Plant Agriculture, University of Guelph, Guelph (Ontario), Canada N1G 2W1; 'USDA-ARS and Department of Horticulture, University of Wisconsin, Madison, Wisconsin, USA 53706

Cavity spot of carrot, caused by several species of Pythium, is endemic in many carrot production areas of the world, including the Holland/Bradford Marsh region of Ontario, Canada. Field trials were conducted 
from 2002 to 2004 to determine if carrots with different pigments varied in susceptibility to the disease, and to study the effect of temperature and rainfall on cavity spot severity. Carrots from the USDA breeding program at the University of Wisconsin were seeded in muck soil (pH 6.4, 60\% organic matter) on 28,30 and 27 May, harvested on 22, 22 and 23 October, and assessed for disease on 5, 8 and 10 December 2002, 2003 and 2004, respectively. The carrots were white (W 105-7), yellow (W 102-1), dark orange (W101-23), red (W 104-3) and purple (W 106-3). Cultivar Cellobunch was included in 2003 and 2004. Disease incidence and severity was assessed on 25 carrots of each of four replicate plots in 2002 and 2003, and on 50 carrots per replicate in 2004. A disease severity index (DSI) was calculated based on the size of the largest lesion per carrot. Disease incidence was moderate in 2002 and 2003 (34 and 33\%), and high in $2004(60 \%)$. Monthly average temperature or rainfall during the growing season was not related to incidence or severity of cavity spot. Consistent differences in susceptibility to cavity spot were identified among the lines. The purple carrot had the lowest incidence $(12 \%)$ and severity (7 DSI) of cavity spot, followed by the dark orange carrot $(39 \%, 22$ DSI), as compared with the susceptible yellow carrot $(58 \%$, $41 \mathrm{DSI})$. There was no difference in disease reaction between the yellow and white carrots. Cellobunch had the same reaction as the dark orange carrot. Studies are needed to determine whether the pigments themselves cause differences in the disease response, and to determine the relative effects of genetics, site and weather on the severity of cavity spot.

\section{Influence of trimming of the carrot canopy on leaf blight severity, fungicide efficacy and deve- lopment of apothecia of Sclerotinia sclerotio- rum \\ M.R. McDonald', K. Vander Kooi', M.H.Y. Hovius', and G.J. Boland'. 'Department of Plant Agriculture; 'Department of Environmental Biology, University of Guelph, Guelph (Ontario), Canada N1G 2W1}

Trimming of the carrot canopy is used in commercial carrot production in the western United States to manage Sclerotinia rot of carrot. Field trials were conducted from 2002 to 2004 to determine the efficacy of this cultural practice on the development of apothecia of Sclerotinia sclerotiorum for the management of Sclerotinia rot of carrot in the Holland/ Bradford Marsh area of Ontario. It was speculated that trimming might also reduce foliar blights (caused by Alternaria dauci and Cercospora carotae) by increasing air circulation within the canopy and allowing for better fungicide coverage. Therefore, the effect of trimming, alone and in combination with fungicide application, on leaf blight development was also investigated. The carrot canopy was left untrimmed or trimmed vertically once or twice to $60 \%$ of the canopy. Weekly sprays with Lance (boscalid, $0.32 \mathrm{~kg} \mathrm{ha}^{-1}$ ) were applied to one half of each plot. The number of apothecia that developed each year was highest in untrimmed plots and decreased as the number of trims increased. However, no symptoms of
Sclerotinia rot of carrot developed in any years, so it was not possible to determine the effects of trimming on this disease. Application of Lance reduced leaf blight severity, but trimming did not reduce leaf blight and combining trimming and fungicide application did not improve disease control. This work confirms an earlier report that trimming the carrot canopy reduces the number of apothecia that develop, and is the first study to investigate the effect of trimming on carrot leaf blights. Trimming of the carrot canopy had no effect on yield.

\section{Current researches performed at INRA on soil- borne diseases of carrot}

F. Montfort ${ }^{1}$, D. Breton ${ }^{1,2}$, C. Béasse ${ }^{1,3}$, and F. Suffert'. 'INRA, UMR BiO3P, B.P. 35327-F-35653 Le Rheu cedex, France; '2SILEBAN, 50760 Barfleur, France; ${ }^{3}$ AIREL, 47110 Sainte-Livrade, France

The "Epidemiology, Soil and Systems" team of the INRA research group at Rennes, France, studies the epidemiology of soil-borne diseases with the aim of identifying environmental factors (climate, cropping practices) that explain disease dynamics and developing management strategies that are adapted to different production situations. In this context, carrot root diseases have been studied since 1980, in close relationship with extensive services and growers associations. The most common pathogens occurring on carrot roots in the main producing areas (Aquitaine, southwest of France, and Normandy, northwest of France) are: 1) Pythium spp. (mainly $P$. violae and $P$. sulcatum), which are responsible for various root disorders occurring during root growth, such as root dieback and cavity spot; 2) Phytophthora spp. ( $P$. megasperma and another species close to $P$. porri isolated from typical symptoms), which are causal agents of ring rot disease; and 3) Rhizoctonia solani (mainly AG2-2 and AG4), which produces damping-off on young stands and typical dark brown lesions around lenticels. Methodologies for characterization of these fungi have been developed based on molecular tools and complemented with knowledge on morphological and general biological features of the various species. For some species of Pythium, specific detection on young plants by Nested-PCR is effective, and we now aim at developing such methods for direct detection in soil. All these diseases are strictly soil-borne with typically polyetic epidemics. Even if the dispersal within a host crop does occur, it is quite limited compared with aerial diseases, and build-up of the disease to epidemic levels requires several susceptible crops over several years. Research on environmental factors acting on the development of soil-borne fungi such as Pythium and Rhizoctonia solani therefore have to be performed at the crop succession scale to identify disease management practices. For cavity spot disease, the polycyclic nature of the epidemic has been demonstrated and the impact of various cropping factors within a season on the different processes, i.e. primary and secondary infections, is being studied. For Rhizoctonia solani, responsible for damage on many crops, an important knowledge database is available and the epidemic processes are more docu- 
mented than for cavity spot. Our objective is to analyze the potential effects of a break-crop (Brassica juncea) acting between seasons to reduce risks by studying the mechanisms involved according to the epidemiological attributes of this pathogen. This research area requires close partnerships with agronomists and plant breeders to define the suitable crop management conditions in the considered agrosystem.

\section{Comparison of key nutritional components of selected carrot cultivars grown in Alberta}

C. Neeser and D. Driedger. Alberta Agriculture Food and Rural Development, Brooks (Alberta), Canada T1R 1E6

Alberta provides excellent agronomic conditions for carrot production. There are few pest problems and a good supply of irrigated land. In spite of these advantages Alberta produces only $5 \%$ of Canadian carrots. In order to better serve customers' needs, producers in this province could benefit from more detailed information on the compositional profile of carrot cultivars. With this study, our objective was to provide key nutritional information on a range of carrot varieties recommended for use in Alberta. In 2003, 15 carrot cultivars were grown in a randomized complete block design with four replications. Each plot consisted of a $4.0 \mathrm{~m}$ twin row planted on a raised bed. In addition to the standard agronomic data, we measured extractable juice, soluble solids, chroma, and concentrations of beta-carotene, fructose, glucose, sucrose, and calcium. Measurements were taken at the beginning of the storage period and after 4 months. We found that total sugar declined on average by only $0.3 \%$, but in one case it increased by $18 \%$. The average sugar content was higher $(6.0 \%)$ than what is typically reported for carrots (4.5\%). Sucrose was the most important component, representing on average $75 \%$ of total sugar. However, varieties low in sugar had a greater proportion of fructose and glucose. Beta-carotene ranged between 71 and $106 \mathrm{ppm}$. These values were consistent with what is commonly reported for these varieties. There were only small differences in chroma (measured on diced carrots), which was somewhat correlated with the betacarotene concentration $(r=0.57)$. Calcium content was consistent with the literature, ranging from 246 to $411 \mathrm{ppm}$, with an average of $328 \mathrm{ppm}$. The information generated from this project will help us to select cultivars that can be used as ingredients in products targeted at the health conscious consumer.

\section{Morphology, inheritance and mapping of a yel- low leaf mutant of carrot, Daucus carota}

T. Nothnagel' and P. Straka'. 'Institute of Horticultural Crops; ${ }^{2}$ Institute of Plant Analysis, Federal Centre of Breeding Research on Cultivated Plants, Quedlinburg, Germany

A yellow leaf (YEL) mutant was selected in an inbred population of the cultivated carrot Daucus carota. Genetic analysis of 10 segregating $F_{2}$ progenies and the corresponding $31 \mathrm{~F}_{3}$ families indicates that the phenotype expressed is controlled by a single recessive nuclear gene. The mutant is stably inherited and is associated with a reduced leaf biomass of approximately $30 \%$ compared with the wild type. A reduced chlorophyll A content was detected by RAMAN spectroscopy. AFLP markers were developed and used in bulked segregant analysis (BSA). Seventeen marker candidates were detected by using 45 primer pairs. A good fit to a 3:1 ratio $(P=0.19-1.00)$ for band presence to band absence for each of the 10 markers was observed in a $F_{2}$ population with 41 plants. A linkage group was constructed with the JoinMap 3.0 program. The integrated location of the YEL locus and 10 AFLP markers was obtained. The linkage group spanned a length of $33.2 \mathrm{cM}$. Nine markers showed coupling linkage with the wild-type allele of the YEL locus. The markers AGL15 and AGL2 flanked the target locus by 0.1 and $0.2 \mathrm{cM}$, respectively. The marker AYL14 selected in the mutant bulk expressed a band in all the yellow plants and 19 of the wild-type plants of the $F_{2}$ population. It was placed $2.5 \mathrm{cM}$ from the YEL locus. Comparisons with the $F_{3}$ families showed an AYL14 marker band expressed in heterozygous plants only. Further investigations will clarify whether the AYL14 marker can be used as a co-dominant marker. The $F_{3}$ studies suggest a stable inheritance and expression of the postulated genotypes. This approach allowed the identification and propagation of homozygous families of both wild-type and yellow leaf mutants. Seeds of the homozygous lines are available. These lines could be of interest as simple morphological markers for genetic experiments. Moreover, the material may be important in studying the photosynthesis of carrot.

The compressed lamina (COLA) mutant of carrot: morphology, inheritance and mapping T. Nothnagel', R. Ahne', and P. Straka'. 'Institute of Horticultural Crops; ' 2 nstitute of Plant Analysis, Federal Centre of Breeding Research on Cultivated Plants, Quedlinburg, Germany

A compressed lamina mutant at a locus named COLA was selected in an inbred population of the cultivated carrot Daucus carota sativus. The mutant plants exhibit a semi-dwarf phenotype. Detailed morphological and histological analyses revealed a decreased elongation of epidermis cells and leaf parenchyma as well as generally reduced lamina dimension. The leaves of the mutant indicated two unstemmed leaflet pairs per nodium instead of the one leaflet pair of the wild type. A completely changed flower morphology was observed for the COLA mutant. The flowers seem hypogyneous contrary to the epigyneous flowers of the wild type. The embryo sac is covered by a strongly increased stylopodium. Seed set on mutant plants was very rare, both self- and cross-pollinated. Transversal sections of the stamen showed a partial deformation of the loculi. Pollen development seems to be normal. The genetic analysis of $10 \mathrm{~F}_{2}$ and the 35 corresponding $F_{3}$ populations gave evidence of a monogenic recessive inheritance of the COLA mutant phenotype. Contrary to the monogenic inheritance, the morphohistological observations showed that the COLA gene affects a number of plant organs at different ontogenetic phases. The preliminary studies suggest the COLA gene does not influence the storage root development and the carotenoid biosynthesis. 
Using 180 RAPD primer and 56 AFLP primer combinations, 39 marker candidates were identified and used in the $F_{2}$ analysis. A good-fit to a 3:1 ratio was observed for 26 markers. Twelve of these could be linked with the COLA locus and mapped in a linkage group with a total length of $44.2 \mathrm{cM}$. Despite the strongly reduced female fertility, a sexual propagation of the mutant genotype was possible. Seeds of the homozygous lines are available. The COLA locus seems to code a key factor of carrot ontogenesis, therefore an available mutant line may be very interesting in breeding research and studies of carrot organ differentiation or physiology.

\section{Leaf-morphological characterization of Daucus carota ssp. and possible application in carrot breeding}

T. Nothnagel', R. Ahne', R. Quilitzsch', , P. Straka², and F. Ehrig'. 'Institute of Horticultural Crops; ${ }^{2}$ Institute of Plant Analysis; 3 Institute of Resistance Research and Pathogen Diagnostics, Federal Centre of Breeding Research on Cultivated Plants, Quedlinburg, Germany

Leaves are important plant organs because of the key role they play in photosynthesis, assimilation and transpiration. Different leaf structures develop through evolution, adapt to different environmental conditions, and play an important role in plant protection against biotic and abiotic stresses. A broad variation in leaf structure exists in the genus Daucus but a systematic investigation has never been conducted. This study aims at providing a detailed characterization of histomorphological leaf structures as the basis for a new source of resistance mechanisms that could enhance carrot plant response to biotic and abiotic stress factors. We compared the cultivated carrot Daucus carota sativus (cv. Bolero, Rotin) with the wild relatives D. c. azoricus, D. C. commutatus, D. c. gadecaei, D. c. gummifer, D. c. maritimus, D. C. maximus, D. c. halophilus, D. c. hispidifolius, and $D$. capillifolius. The investigated accessions represent an important gene pool for carrot breeding due to the lack of natural crossing barriers. Histological observations revealed significant differences between the subspecies. Leaf thickness varied between 146-378 $\mu \mathrm{m}$, the thickness of the adaxial and abaxial epidermis layer between respectively 28-70 $\mu \mathrm{m}$ and 16-41 $\mu \mathrm{m}$, and the thickness of the cuticle between 2.9-9.7 $\mu \mathrm{m}$. Cuticle surface and the epicuticular waxy layer were observed using a scanning electron microscope and characteristic structures for some subspecies were detected. Isolated leaf epicuticular wax was analyzed using a Fourier transform infrared (FT-IR) spectrometer (EQUINOX 55, Bruker Optik, Germany). At least 10 characteristic peaks of absorption were detected for the different subspecies in the wavelengths between 650 and $2000 \mathrm{~cm}^{-1}$. A chemical identification of these key bands will be necessary in the future. Recent investigations were focussed on causal correlations between leaf characteristics and resistance against abiotic and biotic stresses. Differences in cuticle permeability to water, detected in laboratory experiments, suggest a potential source for drought protection. A nearly twice greater relative water loss per time unit was measured for the culti- vated carrot compared with D. C. commutatus, D. C. halophilus or D. c. gadecaei. Furthermore, infection experiments with Alternaria dauci spores clearly showed differences in the time necessary for mycelium penetration after leaf inoculation. On cultivated carrot, Alternaria conidia developed germ tubes and penetrated leaves after only a short time whereas on D. c. commutatus conidia developed relatively long germ tubes with a limited number of appressoria.

Progress in genetics and mapping of carrot T. Nothnagel', O. Schrader ${ }^{7}$, P. Straka ${ }^{2}, A$. Kielkowska ${ }^{3}$ K. Gladysz ${ }^{3}, E$. Grzebelus ${ }^{3}, D$. Grzebelus $^{3}$, and $R$. Baranski ${ }^{3}$. 'Institute of Horticultural Crops; ${ }^{2}$ Institute of Plant Analysis, Federal Centre for Breeding Research on Cultivated Plants, Quedlinburg, Germany; ${ }^{3}$ Department of Genetics, Plant Breeding \& Seed Science, Krakow Agricultural University, Krakow, Poland

Carrot genetics has become a target of bilateral cooperation between the Federal Centre of Breeding Research on Cultivated Plant in Quedlinburg, Germany, and the Department of Genetics, Plant Breeding and Seed Science of the Agricultural University of Krakow, Poland. The joint research project is focused on the inheritance and interaction of two recently described mutant genes: yellow leaf YEL and compressed lamina COLA. For this purpose, classical genetics is combined with molecular marker techniques and molecular cytology to develop a molecular linkage map and to localize the genes on carrot chromosomes. Population mapping was obtained from a single $F_{1}$ plant derived from a cross between the two carrot mutant lines. The $F_{2}$ plants expressed four distinct phenotype classes, which segregated exactly in a Mendelian fashion for two independent genes (9:3:3:1; $\left.\chi^{2}=5.54 ; P=0.14\right)$. Genomic DNA used for molecular evaluation was isolated from leaves of the individual $F_{2}$ plants. A total of 19 RAPD and 136 AFLP markers have been developed for this population and used for a linkage analysis with the two morphological mutant loci. Additionally, a codominant marker for chalcone synthase DcCHS2 gene, developed on the basis of the length polymorphism within the first intron of the gene, was included. A preliminary skeletal linkage map, constructed using the JoinMap3.0 program, contains 60 markers distributed in nine linkage groups for a total of $363 \mathrm{cM}$ in length. Both target genes are localized in separate linkage groups. DNA probes of $5 S$ and $18 S / 25 S$ rRNA, $D c M A D S 3$ and DcFLO genes were used for fluorescence in situ hybridization (FISH). The $18 \mathrm{~S} / 25 \mathrm{~S}$ and $5 \mathrm{~S}$ rRNA probes were localized on the chromosomes 1 and 5 , respectively, in earlier experiments. DcMADS3 and $D C F L O$ were detected on distinct chromosomes at the pachytene stage of meiosis. They are not colocalized with the $18 \mathrm{~S} / 25 \mathrm{~S}$ and $5 \mathrm{~s}$ rRNA probes. A final chromosomal assignment is in progress. 
Impact of crop management on Sclerotinia rot, foliar growth and yield of carrots in Prince Edward Island

R.D. Peters and K.R. Sanderson. Agriculture and Agri-Food Canada, Crops and Livestock Research Centre, Charlottetown (Prince Edward Island), Canada C1A 4N6

Field trials were established in Brookfield, Prince Edward Island, to examine the effects of crop fertility, seeding rate and canopy mowing on yield, and the incidence of Sclerotinia rot in carrots. Increasing the applied rate of nitrogen increased canopy mass and subsequent disease development in petioles and carrot roots. Total and marketable carrot yield was also increased by the addition of higher nitrogen levels. Application of a nitrogen top-dress at mid-season had no effect on yield or disease severity. Lobster processing waste was not adequate as an alternative source of nitrogen for plant growth and yield. Increasing seeding rate from 46 to 112 seeds per $\mathrm{m}$ increased canopy mass as well as the severity of Sclerotinia rot in the foliage and roots. Marketable carrot yield was maximized at 82 seeds per $\mathrm{m}$ and declined on either side of this optimum rate. Lateral clipping of the carrot canopy at row closure significantly reduced the severity of Sclerotinia rot in the foliage as well as in stored carrots, although total and marketable yield was also reduced. These studies suggest that managing carrot canopy by adjusting crop fertility, seeding rate, and with canopy clipping may be viable methods for controlling Sclerotinia rot of carrots.

\section{Pyramiding IPM strategies for improved man- agement of carrot foliar diseases \\ P.M. Rogers and W.R. Stevenson. Department of Plant Pathology, University of Wisconsin- Madison, Madison, Wisconsin, USA 53706}

Foliar diseases caused by Alternaria dauci and Cercospora carotae pose an annual threat to the commercial production of carrots throughout North America. Carrot producers in Wisconsin rely on repeated applications of chlorothalonil to diminish the impact these pathogens have on crop yield, quality and value. Large-scale field trials were conducted within commercial production fields to examine a multifaceted approach to disease control utilizing fewer fungicide inputs. Components of disease management included resistant cultivars, foliar disease monitoring (scouting), and weather-timed fungicide applications alternating chlorothalonil and azoxystrobin. Application intervals were determined by onsite microclimate data collected by in-canopy sensors located at each farm. Equivalent or improved yields, root quality and value were achieved with the multifaceted approach using one to three fewer fungicide sprays compared with the grower standard calendar program. Fungicide inputs were reduced by $50 \%$ (two versus four sprays) on resistant cultivars such as Bolero and Carson, and similar control was observed with four sprays versus six or seven sprays on susceptible lines Heritage or Indiana. A pyramidal multifaceted approach to disease control offers conside- rable benefit to the Wisconsin carrot industry by reducing inputs without compromising disease control or crop yield.

\section{Carotenoid gene expression in developing car- rot roots}

M. Rivera' and P.W. Simon'2. 'Plant Breeding and Plant Genetics Program, Department of Horticulture; ' $U S D A-A R S$ and Department of Horticulture, University of Wisconsin, Wisconsin, USA 53706

Carotenoids are widely distributed in plants and they form one of the largest groups of pigments that are responsible for the yellow, orange and red coloration of tissues. Carrot (Daucus carota) is an important contributor of carotenoid pigments in the roots. Some of the putative copies of the conserved genes coding for the carotenoid biosynthetic enzymes have been sequenced and mapped in a few species, including carrot. Early studies demonstrated that the accumulation of carotenoid pigments parallels fruit maturation, but up to now, no study has been carried out on the gene expression of the carotenoid biosynthesis structural genes in carrot roots. In this research, we quantify the gene activity in carrot roots by following RNA levels with real-time PCR in different root colours (purple, orange, yellow, red, cultivated white, and wild white Queen Anne's Lace). Plants were grown in the greenhouse and tissues were harvested every 3 wk for 4 months. PCR quantification was achieved by measuring the increase in fluorescence during the exponential phase of PCR. Gene expression was observed for most enzymes in the carotenoid biosynthetic pathway for all root colours.

\section{A portrait of Canadian carrot production}

K. Sanderson. Agriculture and Agri-Food Canada, Crops and Livestock Research Centre, Charlottetown (Prince Edward Island), Canada C1A 4N6

Agriculture is the third largest employer in Canada. Total vegetable production contributes about $\$ 1.5$ billion to the economy. While potatoes account for about two-thirds of this total, other vegetables are quite significant contributors. The carrot crop is one of the most important vegetable crops, and Canada is practically self-sufficient in carrot production. Carrots are grown in all ten provinces, with Quebec and Ontario representing about $75 \%$ of the total production. In 2004, about 9500 ha of carrot were planted. In general, since 1994, carrot production by province has increased slightly, except for Ontario and Quebec where production has increased and decreased by 500 ha, respectively. Carrots are produced on both mineral and muck soils (Quebec and Ontario). Field production systems vary from region to region. The most common pests are aster leaf hopper, carrot weevil, carrot rust fly and nematodes. Cercospora and Alternaria leaf blight and Sclerotinia rot are major diseases in Canadian production. Generally, carrots are produced for the fresh market and for processing. There is a significant volume of carrots placed in winter storage for sale during November to the end of March. As in other regions of the world, cut and peel 
has replaced a large amount of the traditional cello pack market. Markets include local, export to the USA, in particular the eastern seaboard, and to the Caribbean. The Canadian carrot industry faces many challenges. These include the need for new, improved varieties, more effective environmentally friendly pest control strategies, the high cost of transportation and the continuous development of markets. Research plays an integral role providing support to this crop and is carried out at AAFC Centres such as Crops and Livestock Research Centre, Charlottetown, Prince Edward Island; Horticultural Research and Development Centre, Saint-Jean-sur-Richelieu, Quebec; Nova Scotia Agricultural College, Truro, Nova Scotia; and University of Guelph, Guelph, Ontario. Industry, growers and provincial governments also contribute substantially to research.

Effect of Hydra-lime Plus on nutrient content, yield and storage of fresh pack carrots in Prince Edward Island

K. Sanderson and S. Wyand. Agriculture and Agri-Food Canada, Crops and Livestock Research Centre, Charlottetown (Prince Edward (sland), Canada C1A 4N6

Fertile mineral soils in Atlantic Canada have shown little response to application of N, $\mathrm{P}$ and/or $\mathrm{K}$ fertilizers. General recommendation for soil $\mathrm{pH}$ and soil $\mathrm{Ca}$ is 5.5-6.5 and $>800$ ppm, respectively. Field trials were established in Brookfield, Prince Edward Island, to examine the impact of adjusting soil $\mathrm{pH}$ on nutrient content and yield of fresh pack carrots. Increasing rates of Hydra-lime Plus ( $\mathrm{Ca}=32 \%$; $\mathrm{Mg}=4 \%$; $\mathrm{S}=$ $1.8 \%$ ) were evaluated at 12 sites over a $3-y r$ period. Hydra-lime Plus did not affect marketable yield. Applications of Hydra-lime Plus increased soil $\mathrm{Ca}$, $\mathrm{Mg}, \mathrm{S}$ and $\mathrm{pH}$. Leaf tissue $\mathrm{S}$ was increased; however, $\mathrm{Ca}$ and $\mathrm{Mg}$ were not affected by treatment. Root $\mathrm{S}$ content was increased at mid-season and harvest. Hydra-lime Plus had a positive effect on the percentage of marketable roots rated after 4 months in storage.

Carrot pigments are bioavailable and under complex genetic control

P.W. Simon', S.A. Tanumihardjo², B.A. Clevidence $^{3}$, J.A. Novotny ${ }^{3}$, S.J. Britz ${ }^{3}$, and M. McGiffen'. 'USDA-ARS Vegetable Crops Research Unit, Department of Horticulture; ${ }^{2}$ Department of Nutritional Sciences, University of Wisconsin-Madison, Madison, Wisconsin, USA 53706; ' $U S D A-A R S$, Beltsville Human Nutrition Research Center, Beltsville, Maryland, USA 20705; ${ }^{4}$ Department of Botany and Plant Sciences, University of California-Riverside, Riverside, California, USA 92521-0124

Carrot breeding stocks are being developed with distinctive dark orange, red, yellow and purple colour. Nutritional studies of these diverse carrots demonstrated that alpha- and beta-carotene in typical orange and dark orange carrots, lycopene in red carrots, lutein in yellow carrots, and anthocyanins in purple carrots are all bioavailable. Using crosses between wild white, cultivated orange and cultivated purple carrots, we have placed the two major genes differentiating white from orange, 25 of the carotenoid biosynthetic enzymes, and the major gene conditioning purple root colour on the carrot genetic map. Selected entries are being extensively tested in the field with emphasis on good flavour. As we develop "nutritionally enhanced" carrots, genetic and nutritional information will be useful for carrot researchers as well as the vegetable industry and consuming public.

\section{Maturity, yield and quality modeling for pro-} cessing carrots

A. Stiles and R. Lada. Processing Carrot Research Program, Nova Scotia Agricultural College, Department of Plant and Animal Sciences, Truro (Nova Scotia), Canada B2N 5E3

In producing carrots for freeze processing, one of the major challenges is timing harvest so as to have a continuous supply of raw material at desired quantities for the processing facility to meet the needs of the various product lines. At times, producers need to harvest their crop without knowing whether the crop has reached optimum maturity and quality, which may in turn lead to sacrificing yield and profits. In a production system, carrot growth and maturity may be greatly influenced by environmental weather conditions in addition to management inputs through their intrinsic processes connected with carbon fixation and utilization. Thus, an understanding of crop maturity, bulking and quality of various processing carrot varieties, and identifying environmental/weather parameters would help in understanding and predicting crop growth and yield. Models integrating weather parameters would provide a useful tool in production, process planning and decision making. Field trials were conducted in five locations in Colchester and King's county, Nova Scotia, during the 2004 growing season. A total of nine carrot varieties (three dicer, three slicer and three cut and peel varieties) were sown in commercial scale plots. There were three locations for each of the slicer and dicer varieties and two locations for the cut and peel varieties. Weather stations were placed in the fields to collect data on air temperature, rainfall, solar radiation, relative humidity, soil temperature, wind speed and direction from which degree days and evaporation were calculated. Soil moisture was monitored in each field throughout the season. Sampling began when the plants were approximately 4-6 wk old and was continued biweekly through final harvest. Measurements were made on plant stand, leaf biomass (top growth), root girth, length and gross yield. Recovery of marketable grades was also measured after the final yield was determined. Cumulative data was compiled for all of the weather parameters measured to coincide with the sampling dates. Weather stations recorded approximately 800 growing degree days and $235 \mathrm{~mm}$ of rainfall between seeding and final harvest in the King's county locations. Colchester county fields had slightly less rainfall $(225 \mathrm{~mm})$ and fewer growing degree days (700). Among dicer varieties, Euforo and RCC bulked at a faster rate than Prodigy while RCC had the largest root girth at final harvest. It was observed that bulking in the slicer 
varieties sharply increased after the third week in July compared with the dicer and cut and peel varieties, for which bulking occurred at a constant rate throughout the growing season. Correlations between carrot development and cumulative weather parameters were performed and models were developed. $R^{2}$ values for yield vs. cumulative degree days, cumulative rainfall, and cumulative high temperature and cumulative solar radiation for most of the varieties were 0.94 or higher, indicating that all these weather parameters have a strong influence on yield. A software program will be developed using these models for predicting optimal yield and quality, which would aid harvest decision making.

\section{Molecular characterization of different aroma types in Daucus}

P. Straka', T. Nothnagel', and D. Ulrich'. 'Institute of Plant Analysis; ${ }^{2}$ Institute of Horticultural Crops, Federal Centre for Breeding Research on Cultivated Plants, Quedlinburg, Germany

In the past, a genetic map of Daucus carota was established by our team. This map includes molecular markers and morphological traits. The next steps to further our work on the carrot map are the development and localization of Quantitative Trait Loci (QTL). Next to sweetness, aroma is the most important quality parameter of carrot flavour. Up to now, contrary to sugar or colour analyses, estimation of the aroma compound is not implemented in carrot breeding programs. Based on gene bank material, a special $F_{2}$ population was produced with high variation in aroma patterns. This population included 200 plants. The analyses of aroma compounds were carried out on roots of single plants, marker development based on single plant leaf material. The chemical analyses of volatiles were estimated based on a combination of automated headspace solid phase microextraction (SPME) as sample preparation, fast gas chromatography (GC) and chemometrical pattern recognition as a rapid and convenient method. More than 50 volatiles were detectable. The development of molecular markers was focused on amplified fragment length polymorphisms (AFLP). About 64 different primer pairs were used and until now, 250 markers have been developed.

\section{Identification and differentiation of plant patho- genic fungi}

P. Straka', T. Nothnagel ${ }^{2}$, F. Rabenstein ${ }^{3}$, and R. Krämer'. 'Institute of Plant Analysis; 'Institute of Horticultural Crops; ${ }^{3}$ Institute of Resistance Research and Pathogen Diagnostics, Federal Centre for Breeding Research on Cultivated Plants, Quedlinburg, Germany

In the Federal Centre for Breeding Research on Cultivated Plants (BAZ), investigations on resistance and/or tolerance against pathogenic organisms are carried out on a large scale within the frame of evaluation programs. Plants invaded by pathogenic fungi may show a variety of responses. Therefore, rapid and sensitive methods for differentiation and identification of these fungi are needed, which permit the control of typical characters of selected isolates.
Furthermore, in some cases, uncharacterized isolates of fungi must also be compared. Altogether, 27 isolates belonging to species of the genera Alternaria, Fusarium, Septoria and Phoma were included in our studies. Characteristics of these fungi isolates were determined based on morphological and serological investigations as well as by random amplified polymorphic DNA (RAPD) analysis. DNA polymorphism of fungi associated with RAPD markers was successfully applied for species identification although the method was not sufficient for differentiation of isolates of the same species. The limitation of the approach is due to the narrow genetic variation of the different isolates and also to the restricted sensitivity of the RAPD separation and detection method. After PCR reaction, RAPDs were often separated by agarose gel electrophoresis and determined by specific staining substances. The aim of the investigations presented here was the identification of different fungi isolates using serological methods and polyacrylamide gel matrix with DNA silverstaining for a more sensitive separation and detection. Based on the changes of separation and staining methods of RAPD marker bands, a high level of polymorphism between different accessions of pathogenic fungi could be detected and therefore the differentiation and determination of relationships among isolates were successful. For detection of Alternaria dauci, a polyclonal antiserum to surface washings was produced in rabbits and applied in plate-trapped antigen (PTA) ELISA for detection of mycelium amount in infected carrot leaves. In PTA-ELISA and Western blotting (WB) experiments, the antiserum showed cross-reactions with cultures in all tested Alternaria species although the characteristic pattern produced by each species in WB could be used for discrimination. Further experiments must be carried out to determine whether WB experiments will be reproducible for differentiation of isolates of the other above-mentioned species. In order to improve test sensitivity and specificity, the development of monoclonal antibodies appears to be advantageous.

\section{Effect of three cropping factors on secondary infection in a carrot cavity spot epidemic} F. Suffert, D. Delalande, and F. Montfort. INRA, UMR BiO3P, Epidémiologie, Sol et Systèmes, 35653 Le Rheu Cedex, France

Cavity spot of carrot (CSC), one of the most important soil-borne diseases on this crop in the world, is characterized by the appearance of small sunken lesions on the taproot due to a Pythium pathogenic complex, in part composed of $P$. violae and P. sulcatum. Soil inoculum of several soil-borne diseases is the source of "primary infection", and new diseased plants can serve as the inoculum source and support "secondary infections", i.e. autoinfection on the same root and alloinfection by the spread from root to root. Our objectives are to develop epidemiological studies on CSC based on these classical mechanistic hypotheses (occurrence of primary and secondary infections) and to test the effects of cropping factors according to the CSC epidemic stage. An infestation method was specifically developed to demonstrate and generate cycles of secondary infection of CSC in controlled 
conditions, and establish the polycyclic nature of a CSC epidemic. To this purpose, an original methodology consisting of artificial inoculation of a thickened carrot root (the "donor plant") before transplantation in a microcosm was described. This reproducible method generated methodological advances to delay inoculation and distinguish the effect of different cropping factors or treatments on primary and secondary infections: soil moisture (irrigation), seed density and fungicide treatment. We first demonstrated that CSC lesions on carrot residues are potentially infectious for healthy roots, using fragments of lesions due to $P$. violae as soil inoculum, and secondly we proved the ability of CSC to spread from root to root by alloinfection, using a live transplanted root after artificial inoculation. We tested in microfields the effect of soil moisture on an entire epidemic (primary and secondary infections) using a sprinkler irrigation system; in moderately and intensively irrigated soils, disease levels were significantly higher than in non-irrigated soils. We showed in microcosms an effect of the distance between the source of inoculum (the donor plant) and the target healthy roots (the receptor plants) on secondary infection. We also established an effect of seed density: a lower density is responsible of a smaller total diseased area on the target roots. This study produced other information about the propagation of $P$. violae: the maximal distance for successful secondary infection is at least $90 \mathrm{~mm}$ and the latency period is between 1 and 2 wk. Finally, a fungicide (mefenoxam), which is currently used before seed emergence by growers, was able to reduce the secondary infections in microcosms when sprayed during the cropping season, thus slowing the progression of the disease in time and space. Understanding the role of infection processes is now crucial for designing a holistic approach to manage CSC, which includes both preplanting control measures, such as crop rotation, disinfection and introduction of break-crops to limit primary infections, and post-planting measures such as fungicide, control of irrigation or date of harvest to limit the secondary infections. Research is now needed to organize the knowledge about the effects of various methods on Pythium communities and determine their impact on each process, primary or secondary infection, with a distinction between autoinfection (to reduce symptom intensification on the root) and alloinfection (to reduce spatial extensification between adjacent roots).

Researches are partly supported by fundings from Section Nationale Carotte, FEDER, Regional Councils (Basse-Normandie and Aquitaine).

\section{Control of environmental conditions for carrot storage: Why and how?}

C. Vigneault ${ }^{1}$, N.R. Markarian², J.A. Landry3, M.T. Charles', and V. Toussaint'. 'Agriculture and Agri-Food Canada, Horticultural Research and Development Centre, Saint-Jean-sur-Richelieu (Quebec), Canada J3B 3E6; '2Department of Bioresource Engineering, Faculty of Agricultural and Environmental Sciences, Macdonald Campus of McGill University, Sainte-Annede-Bellevue (Quebec), Canada H9X 3V9;
${ }^{3}$ Automated Production Engineering, École de technologie supérieure, Université du Québec, Montréal (Quebec), Canada H3C 1 K3

In this project, two aspects of controlling ambient storage conditions for carrot, namely how and why we should do it, were evaluated. The first part involves a state-of-the-art enthalpy-based (h-B) controller to manage the multivariable processes encountered in horticultural storage facilities. This new controller includes Proportional Integral Derivative (PID)-like loops to control temperature and relative humidity. The idea is that since enthalpy encompasses both temperature and relative humidity, it should eliminate the undesired instability resulting from the coupling effect of temperature and relative humidity encountered with conventional controllers. The theoretical evaluation of the performance of an $\mathrm{h}-\mathrm{B}$ controller shows the net advantage of using this system based on the uniformity of ambient storage conditions over time when compared with the use of on/off and conventional PID controllers. The h-B controller quickly reached the desired conditions after a short stabilization period, the h-B PID controller provided the most stable temperature and relative humidity control, while the on/off and PID controllers resulted in cyclic responses. This cyclic response caused by the coupling effect of temperature and relative humidity is eliminated when using the proposed h-B PID controller. In the second part, some results were derived from the measurement of the uniformity of ambient conditions in four instrumented commercial storage rooms during two consecutive seasons. Their impact on the quality of the stored commodities, namely carrots, was evaluated. In brief, the quality of the instrumentation was such that it was possible to evaluate the uniformity of ambient conditions for each room. In general, the humidity level reached $97 \%$ quickly when the storage room was filled with carrots. However, the results also show a more uniform temperature and relative humidity in room $A$ than in the others. Room $A$ was the only room equipped with a control system that considered the outside air temperature to calculate the amount of outside air required to maintain the desired storage conditions. In room $A$ the incoming air was first circulated in a mixing-chamber to be combined with inside air before coming in contact with the produce. This approach provided better environment stability when compared with the other three rooms. Finally, when comparing the results, room A presented significantly less disease incidence than the other three rooms, which did not exhibit any significant difference.

\section{Use of biofumigation in carrot culture for con- trolling soilborne pathogens}

F. Villeneuve', G. Maignien', C. Janvier ${ }^{2}$, and C. Steinberg ${ }^{3} .{ }^{1}$ Ctifl, Centre de Lanxade, F $24130 \mathrm{La}$ Force, France; ${ }^{2}$ Ctifl/INRA, UMR MGS, CMSE, F 21065, Dijon, France; ${ }^{3} I N R A$, UMR MGS, CMSE, F 21065, Dijon, France

Biofumigation, a new method for controlling soilborne plant pathogens, was tested for its efficacy on Rhizoctonia solani and Pythium spp. in semicontrolled and field conditions. Biofumigation is a 
technique that aims at using the effects of incorporating organic matter (fresh or otherwise) in order to reduce the impact of soilborne diseases. It involves supplying a given quantity of organic matter (or, as a preliminary, cultivating a plant selected for these qualities, and preferably for its strong development), crushing it, incorporating it superficially, and then sealing the soil either by a cover or by rolling. Plots were amended with different fresh amendments (Indian mustard, Brassica juncea cv. Swollen Stem; white mustard, Sinapsis alba cv. Gisalba; fodder radish, Raphanus sativus cv. Résal and Commodore; sudangrass, Sorghum sudanense cv. Trudex; and leek, Allium ampeloprasum var. Porrum cv. Prélina) at $4.0 \mathrm{~kg}$ fresh weight $\mathrm{m}^{-2}$ and covered with plastic or left uncovered. Physicochemical $\mathrm{CO}_{2}, \mathrm{CO}_{2}$, temperature, nitrogen), biological, molecular and phytosanitary properties were measured and analyzed. In plots amended with fresh organic amendments and covered with plastic sheets, strong anaerobic conditions developed quickly, as indicated by rapid depletion of oxygen and an increase in carbon dioxide rates. We also observed a modification of the nitrogen cycle with an accumulation of $\mathrm{NH}_{4}{ }^{+}$during the covering period. In the few days after the tillage and the covering, we observed an increase in $\mathrm{NH}_{4}{ }^{+}$and then a decrease. Biofumigation resulted in a significant increase in microbial densities and biomass, and modified microbial community structures. In these conditions we observed an important reduction in Rhizoctonia solani damping-off and a reduction in alteration of roots by Pythium spp. Various parameters can play a part, such as the nature of the incorporated fresh organic amendments, the temperature during coverage, the type of mulching, and the modification of the nitrogen cycle. These results show the potential for this approach to control $R$. solani and Pythium spp. in carrot production.

\section{Carrots: Potential as a nitrogen catch crop?}

S.M. Westerveld, M.R. McDonald, and A.W. McKeown. Department of Plant Agriculture, University of Guelph, Guelph (Ontario), Canada N1G 2W1

With increasing environmental concerns over the excess use of nitrogen ( $N$ ) fertilizers, there is a need to re-evaluate the $\mathrm{N}$ requirements of vegetable crops. Carrots grown in temperate regions often require little applied $\mathrm{N}$ for optimal yields. Field experiments were conducted to determine the $\mathrm{N}$ requirements of carrots on mineral and organic soils and to evaluate the potential of using carrots as an $\mathrm{N}$ catch crop to remove excess $\mathrm{N}$ from the soil. "Idaho" and "Fontana" carrots were grown on both mineral and organic

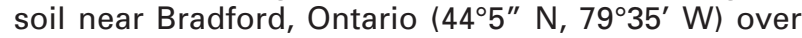
$3 \mathrm{yr}$, from 2002 to 2004. Nitrogen was applied as ammonium nitrate at $0,50,100,150$, and $200 \%$ of Ontario recommended rates (organic soil: $60 \mathrm{~kg} \mathrm{ha}^{-1} \mathrm{~N}$ pre-plant; mineral soil: $75 \mathrm{~kg} \mathrm{ha}^{-1} \mathrm{~N}$ pre-plant/ $35 \mathrm{~kg}$ $\mathrm{ha}^{-1}$ side-dress). Tissue samples were collected biweekly on selected treatments over the season to develop an $\mathrm{N}$ budget of the crop and to identify the pattern of $\mathrm{N}$ uptake over the growing season. Yield and quality were assessed at harvest. Total yield was unaffected by the rate of applied $\mathrm{N}$ on organic soil in all three years and on mineral soil in 2002. Total yield of carrots grown on mineral soil increased with increasing $N$ rate in 2003, and increased up to a maximum at $90 \%$ of the recommended $\mathrm{N}$ rate in 2004 . Nitrogen rates at or above the recommended rate in 2004 resulted in seedling death and subsequent yield loss on mineral soil. Root quality was not affected by $\mathrm{N}$ rate in any trials. Carrots were shown to take up nearly $250 \mathrm{~kg} \mathrm{~N} \mathrm{ha}^{-1}$ over the growing season. Carrots are capable of extracting a high amount of $\mathrm{N}$ from the soil without $\mathrm{N}$ fertilization, and could be used to reduce $\mathrm{N}$ losses in vegetable crop systems.

\section{Nitrogen rate influences the development of Alternaria and Cercospora blights of carrots} S.M. Westerveld, M.R. McDonald, and A.W. McKeown. Department of Plant Agriculture, University of Guelph, Guelph (Ontario), Canada N1G 2W1

Carrot leaf blights, caused by Alternaria dauci and Cercospora carotae, are destructive foliar diseases of carrots in Canada. An important addition to fungicide use is optimal crop nutrition. Field experiments were conducted to determine the relationship between nitrogen (N) application rate and disease severity. "Idaho" and "Fontana" carrots were grown on both mineral and organic soil near Bradford, Ontario

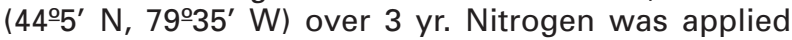
as ammonium nitrate at $0,50,100,150$, and $200 \%$ of Ontario recommended rates (organic soil: $60 \mathrm{~kg} \mathrm{ha}^{-1} \mathrm{~N}$ pre-plant; mineral soil: $75 \mathrm{~kg} \mathrm{ha}^{-1} \mathrm{~N}$ pre-plant/ $35 \mathrm{~kg} \mathrm{ha}^{-1}$ side-dress). Damage from Alternaria and Cercospora was rated biweekly on a scale of 0 to 10 and the area under the disease progress curve (AUDPC) was calculated. The number of lesions per leaf and the number of live leaves per plant were recorded. Carrot cv. Idaho had consistently less leaf blight than cv. Fontana but showed similar responses to $\mathrm{N}$ application rate. In most cases, high $\mathrm{N}$ reduced the AUDPC for both Alternaria and Cercospora on both soil types. Lesions per leaf decreased with increasing rate of $\mathrm{N}$, and the number of live leaves per plant increased with increasing rate of $\mathrm{N}$. These results are consistent with reports that $\mathrm{N}$ application can reduce the severity of Alternaria blight on carrots, and show that the response is similar for Cercospora blight. This is the first study to assess the effects of $\mathrm{N}$ rate alone on both pathogens. Decreasing $\mathrm{N}$ application rates could result in an increased need for fungicide applications. Nitrogen fertilization should be an important consideration in integrated disease management of carrots. 


